Second Department of Internal Medicine, Centre for the Rheumatic Diseases, Lainz Hospital, Vienna, Austria $\mathrm{V}$ Weiler $M$ B Fischer J S Smolen

Jakob Erdheim Institute of Pathology, Lainz Hospital S Redtenbacher

Department of Neurology, Lainz Hospital

C Bancher

Correspondence to: Professor J Smolen, Second Department of Medicine, Lainz Hospital,

Wolkersbergenstrasse 1, A-1130 Vienna, Austria smj@2me.khl.magwien.gv.at

Accepted for publication 18 May 2000

\title{
Concurrence of sarcoidosis and aortitis: case report and review of the literature
}

\author{
V Weiler, S Redtenbacher, C Bancher, M B Fischer, J S Smolen
}

\begin{abstract}
Takayasu arteritis (TA) is a rare manifestation of systemic large vessel vasculitis which affects predominantly the aorta and its main branches, but often remains unrecognised owing to delayed diagnosis and non-characteristic clinical features. Sarcoidosis, too, is a systemic inflammatory disease which can affect virtually any organ system. Reports about the coincidence of both diseases have appeared.

The case presented here is characterised by a significant time lag between detection of TA and appearance of clinical signs of sarcoidosis. The woman, now 39 years old, had erythema nodosum, circumscript alopecia, and recurrent uveitis, which dated back to 1980 and was attributed to sarcoidosis. At least 12 years later aortic valve insufficiency with progressive cardiac failure developed. Histology performed at the time of aortic valve prosthesis in 1997 disclosed a diagnosis of TA, which was confined to the aortic root. Incidentally, sarcoidosis was diagnosed in adjacent lymph nodes. A thorough check up failed to detect further manifestations of TA; thus, possibly, the patients had aortitis similar to, but not identical with, TA. Several related cases previously reported are discussed, suggesting that both diseases may be inherently related as they are characterised by certain non-specific, immunoinflammatory abnormalities. This case report suggests that the prevalence of TA, or related forms of arteritis, may be higher than expected and should be considered, especially in younger patients with non-characteristic cardiovascular symptoms and suspected systemic inflammatory disease. Moreover, the association with sarcoidosis in this and other previously described cases suggests that the two diseases may be related and that TA or TA-like vasculitis may even be a complication of sarcoidosis. (Ann Rheum Dis 2000;59:850-853)
\end{abstract}

Takayasu's arteritis (TA) is a chronic inflammatory disease of the large vessels which affects mainly the thoracic aorta and its branches but can also occur elsewhere in the vascular system-for example, in the pulmonary, the coronary, mesenterial, and renal arteries. ${ }^{1-4}$ Prevalence is highest in younger women and the incidence in the Western hemisphere is around two to three cases per million personyears. Clinically, the disease is characterised by claudication, pulselessness, and asymmetric blood pressure. Hypertension is seen in about half of the patients, especially if the renovascular system is affected. In the early stage non-specific symptoms, such as fatigue, low grade fever, or weight loss, prevail; arthralgia is also a common complaint. Some patients may be asymptomatic, depending on the amount of collateral perfusion. Laboratory findings are non-specific and are usually confined to raised erythrocyte sedimentation rate and mild leucocytosis or normochromic anaemia.

There are no serological markers specific for TA. Diagnosis can be made by angiography, showing changes of the large arteries with stenosis and post-stenotic dilatation. ${ }^{4}$ Histologically, focal pan-arteritis is found, including granulomatous inflammation with infiltration of the media and adventitia by mononuclear cells, histiocytes, and multinucleated giant cells; endothelial cell proliferation and fibrosis of the media lead to progressive narrowing of the lumen. ${ }^{12}$

Sarcoidosis is a systemic granulomatous disease with an incidence of 10 to 40 per 100000 people a year. The lungs are most commonly affected, but often there is also affection of the musculoskeletal system, the cutaneous and central nervous systems, and the heart. Histology shows granulomas consisting of a central zone with macrophages, epithelioid cells, and multinucleated giant cells in addition to activated CD4 lymphocytes, and a peripheral zone with macrophages, fibroblasts, and CD4 and CD8 lymphocytes. Inclusion bodies are commonly found. Vasculitis may be found occasionally in patients with sarcoidosis. ${ }^{5}$ It has not been confirmed, however, whether vasculitis is a true manifestation of the disease or an occasional, incidentally concurring abnormality. There are a few reports of the concurrence of sarcoidosis and various immunological disorders, including different forms of vasculitis. $^{3-9}$ Until now it has remained uncertain whether this coincidence implies any immunological relation. Here we present a rare case of a patient who had aortitis with 

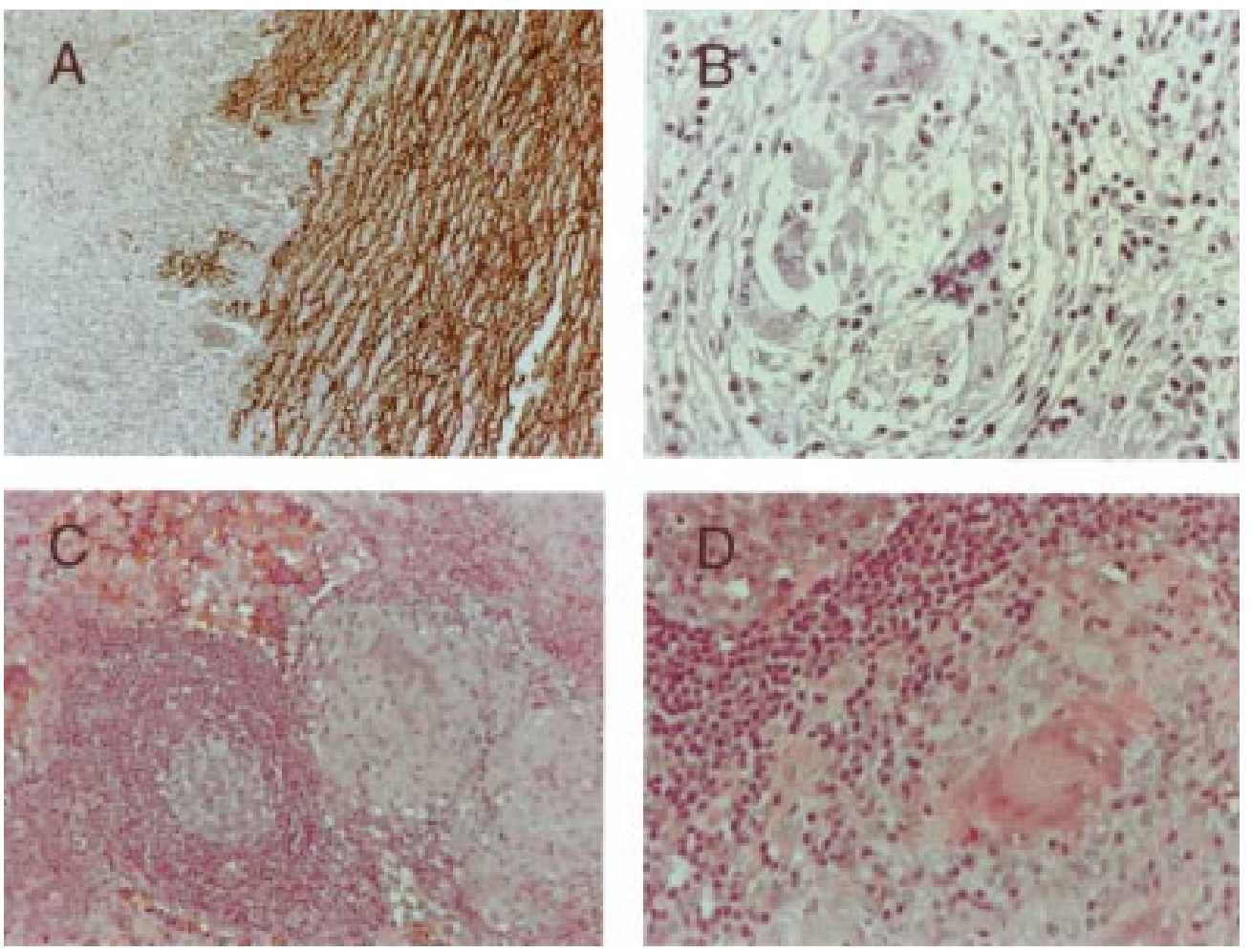

Figure 1 Histopathology of the aortic root $(A, B)$ and a para-aortic lymph node $(C, D)$. For details see text.

histological changes similar to those seen in TA and sarcoidosis. This coincidence has allowed us to gain some insight into a possible relation between the two disorders.

\section{Case report}

In December 1991 a 32 year old woman was admitted to our department because of acute exacerbation of chronic low back pain. Past history of the patient showed mild hypertension and an erythema nodosum of the legs, which had been accompanied by swelling of the ankles and dated back to 1980. At that time sarcoidosis had been diagnosed and steroid treatment started. Three years later, circumscript alopecia had occurred and histology of a skin biopsy specimen confirmed the diagnosis of sarcoidosis. In addition, for about 10 years the patient has had recurrent uveitis, which has required repeated cycles of corticosteroid treatment. The patient has never complained about dizziness, seizures, or thromboembolic events in the past.

On admission in 1991 uveitis and paralumbar tendomyalgia were diagnosed. The patient was treated successfully with analgetic and physicotherapeutic measures. Low dose oral glucocorticoids were given for her uveitis. Laboratory variables showed moderately raised sedimentation rate $(30 \mathrm{~mm} / 1 \mathrm{st} \mathrm{h})$ and $\mathrm{C}$ reactive protein (CRP) $12 \mathrm{mg} / 1$ (normal 0-5). Blood cell count, serum chemistry, and urine analysis were normal. Antinuclear antibodies, rheumatoid factor, C3, C4, anticardiolipin antibodies, and antineutrophil cytoplasmic antibodies were negative or normal. Routine chest radiography was unremarkable. The patient was soon discharged and glucocorticoid treatment gradually tapered.
During the following years the patient developed signs of progressive heart failure with dyspnoea on exertion. Aortic regurgitation of haemodynamic significance was diagnosed by trans-thoracic echocardiography, and an operation for aortic valve prosthesis was undertaken in April 1997. Surprisingly, histological specimens of various parts of the aortic root showed focal dissection and infiltration with epithelioid cell granulomas, predominance of multinucleated giant cells, histiocytes, and focal lymphoplasmocellular infiltration of the adventitia and the peripheral layers of the media; furthermore, rarefaction of smooth muscle cells and elastic membranes of the media was seen (fig $1 \mathrm{~A}$ and $\mathrm{B}$ ). These histological findings in conjunction with the typical localisation of involvement were regarded as typical for TA. However, other features of TA were not found before or after the operation, and therefore another, undetermined type of aortitis cannot be fully excluded. Nevertheless, it must be stated that the patient had negative serology for syphilis and also did not have a seronegative spondyloarthropathy, which together with TA are the most common causes of aortitis.

During the operation an enlarged lymph node of $2.5 \mathrm{~cm}$, situated at the aortic root, was removed. Histology was consistent with the diagnosis of sarcoidosis with numerous epithelioid cell granulomas and occasional multinucleated giant cells (fig 1C and D); staining for mycobacteria was negative.

Postoperatively, chest radiography showed a mediastinal mass, which originally was attributed to perivascular blood accumulation. This finding could be verified by high resolution tomography and the mediastinal mass 
Table 1 Features of related cases with coincidence of sarcoidosis and vasculitis

\begin{tabular}{|c|c|c|c|c|c|c|c|c|}
\hline Features & Watson et al ${ }^{6}$ & Rose et al $l^{10}$ & Taieb et $a l^{13}$ & Kerr et al $(1)^{4}$ & Kerr et al $(2)^{4}$ & Schapiro et al ${ }^{12}$ & Ahuja et al $l^{9}$ & Our case \\
\hline Uveitis & - & + & - & - & + & - & - & - \\
\hline $\begin{array}{l}\text { Classification of } \\
\text { vasculitis }\end{array}$ & See below & $\begin{array}{l}\text { Aortitis } \\
\text { presumably due } \\
\text { to sarcoidosis }\end{array}$ & $\mathrm{TA}^{\star}$ & $\mathrm{TA}$ & $\mathrm{TA}$ & $\mathrm{TA}$ & $\begin{array}{l}\text { Wegener's } \\
\text { granulomatosis }\end{array}$ & $\mathrm{TA}$ \\
\hline $\begin{array}{l}\text { Vasculitic } \\
\text { manifestation }\end{array}$ & $\begin{array}{l}\text { Microscopic } \\
\text { polyangiitis of } \\
\text { kidney }\end{array}$ & $\begin{array}{l}\text { Left subclavian } \\
\text { and both carotid } \\
\text { arteries }\end{array}$ & Aortic arch & $\begin{array}{l}\text { Main branches } \\
\text { of aortic arch }\end{array}$ & $\begin{array}{l}\text { Subclavian steal } \\
\text { syndrome }\end{array}$ & $\begin{array}{l}\text { Aortic bifurcation } \\
\text { both subclavian } \\
\text { arteries }\end{array}$ & $\begin{array}{l}\text { Wegener's } \\
\text { granulomatosis }\end{array}$ & Aortic root \\
\hline $\begin{array}{l}\text { Presenting } \\
\text { symptoms }\end{array}$ & Nausea fatigue & Syncope & $\begin{array}{l}\text { Headache, } \\
\text { hypertension }\end{array}$ & $\begin{array}{l}\text { Polyarthritis, } \\
\text { uveitis }\end{array}$ & $\begin{array}{l}\text { Uveitis, hilar } \\
\text { adenopathy }\end{array}$ & $\begin{array}{l}\text { Arteritis } \\
\text { claudication, } \\
\text { stenocardia }\end{array}$ & $\begin{array}{l}\text { Nausea, fever, } \\
\text { pleuritis }\end{array}$ & Heart failure \\
\hline $\begin{array}{l}\text { Time lag between } \\
\text { diagnosis of } \\
\text { sarcoidosis and } \\
\text { vasculitis }\end{array}$ & 20 years & 8 years & 2 years & 9 years & 0 & 2 years & 5 months & 17 years \\
\hline $\begin{array}{l}\text { Age at manifestation } \\
\text { of vasculitis }\end{array}$ & 50 & 11 & 11 & 13 & 32 & 42 & 39 & 32 \\
\hline Treatment & $\begin{array}{l}\text { NSAIDs*, } \\
\text { Glucocorticoid }\end{array}$ & Glucocorticoid & $\begin{array}{l}\text { Anti-hypertensive } \\
\text { agents }\end{array}$ & n.r. & n.r. & $\begin{array}{l}\text { Glucocorticoid, } \\
\text { cyclophosphamide }\end{array}$ & $\begin{array}{l}\text { IV cyclo- } \\
\text { phosphamide, } \\
\text { glucocorticoid }\end{array}$ & $\begin{array}{l}\text { Surgery } \\
\text { Glucocorticoid }\end{array}$ \\
\hline
\end{tabular}

${ }^{\star}$ NSAIDs $=$ non-steroidal anti-inflammatory drugs; $\mathrm{TA}=$ Takayasu's arteritis; n.r. $=$ not reported

disappeared completely within two weeks. In addition, a $2.5 \mathrm{~cm}$ dilatation of the aortic root of almost round shape was noted, which gave rise to suspicion of a false aneurysm. Transoesophageal echocardiography showed a dilatation of the coronary sinus to $5 \times 3 \mathrm{~cm}$, which was considered to be an anatomical variation; no aneurysm of the aorta was found. Angiography confirmed this finding, with normal morphology of the coronary vessels. The chest radiographs obtained about three months before and two weeks after the operation were comparable, as were the films in the follow up period. Treatment was started with prednisone and oral anticoagulation with phenprocoumon because of her mechanical valve prosthesis.

During the following months the patient had no further medical problems. At a clinical control examination three months postoperatively the patient reported occasional mild back pain, no arthralgia; physical examination was unremarkable. Laboratory testing showed an erythrocyte sedimentation rate of $20 \mathrm{~mm} / 1 \mathrm{st} \mathrm{h}$, blood cell count and blood chemistry were normal, electrophoresis showed an increase of the $\gamma$ globulin fraction to $23 \%$ (upper normal limit $21 \%$ ), total protein was normal. CRP was $18 \mathrm{mg} / 1$ (normal 0-5). Spirometry was normal.

In September 1998, two months after the last clinical visit, the patient developed a transient ischaemic attack, which was localised to the region of the median cerebral artery. ECG showed sinus rhythm. Computed tomography of the aortic arch and branches was normal, as was duplex sonography. Magnetic resonance imaging of the brain showed no abnormalities. Moreover, echocardiography was normal without signs of valvular dysfunction. At a clinical control examination in late 1998 the patient had no significant complaints.

\section{Review of the literature}

Only a few publications on the coexistence of sarcoidosis and vasculitis have appeared. In some of these patients small vessel vasculitis was preceded by sarcoidosis. ${ }^{67}$ Ahuja et al presented a case in which, by contrast, sarcoidosis was preceded by Wegener's granulomatosis. ${ }^{9}$

Occasional reports of patients with sarcoidosis and large vessel disease have also appeared (table 1). The case of a 17 year old girl who developed sarcoidosis at $31 / 2$ years of age and stenosis of the subclavian and carotid arteries eight years later was presented by Rose et al. ${ }^{10}$ Maeda et al reported a case of generalised sarcoidosis with features of aortitis. ${ }^{11}$ Schapiro et al presented a case of hilar lymphadenopathy, restrictive lung disease, and non-caseating skin granulomas ${ }^{12}$; the patient was pulseless at the time sarcoidosis was diagnosed. Taieb et al presented a similar case in a 9 year old boy with a skin rash who exhibited hypertension two years later ${ }^{13}$; follow up disclosed a mixed pattern of stenosis and dilatation of the aortic arch, and histology of the cutaneous lesions showed noncaseating granulomas with epithelioid cells. In this patient hypertension had prompted awareness of large vessel disease.

The scarcity of such case reports in the literature suggests that the association between sarcoidosis and TA or other forms of aortitis may be rare. However, TA or similar forms of aortitis are too rare to indicate that the reported concurrence with sarcoidosis is merely governed by chance. And in fact, in a review of 60 patients with TA, Kerr et al found two cases of sarcoidosis associated with $\mathrm{TA},{ }^{4}$ which are also summarised in table 1 .

All these patients had several common features: (a) usually sarcoidosis preceded TA; (b) the time lag between the diagnosis of sarcoidosis and that of TA was several years (eight or more) in most of the patients; (c) the aorta and/or its major branches was affected; (d) $50 \%$ of the patients had uveitis, which is much less common in frank sarcoidosis; and (e) all patients responded to glucocorticoid treatment. The features in our patient were quite similar, including the presence of uveitis.

\section{Discussion}

The case report presented here describes a patient in whom sarcoidosis preceded the diagnosis of an arteritis affecting the aortic root by many years. Importantly, the patient also had sarcoid lymph node disease concurrent with her aortitis. Sarcoidosis is known possibly to affect many other organ systems, ${ }^{58}$ but involvement of the large vessels is not a recognised feature of the disease. 
The diagnosis of TA-like disease was incidental and the patient did not fulfil all clinical features associated with TA, as the disease manifested itself only by involvement of the aortic root, necessitating valve replacement. However, there are several reports of atypical presentations of TA. ${ }^{14}{ }^{15}$ In our patient, histological abnormalities were typical for $\mathrm{TA}^{14}$ and involvement of the lymph nodes is not a major feature of TA. Additionally, there was no evidence for any of the potential differential diagnoses of $\mathrm{TA}^{1-4}$ : the patient did not have systemic lupus erythematosus, Behçet's disease, Crohn's disease, ankylosing spondylitis, ergotism, syphilis, Buerger's disease, or temporal arteritis. Moreover, the patient's age at the time of diagnosis was typical for TA $(<40$ years). In our patient, mild hypertension was present before signs of cardiac failure appeared. However, she has been normotensive since the time of valve prosthesis, indicating that hypertension was not secondary to involvement of more distal arteries or the distal aorta by arteritis. In accordance with this notion, and although hypertension might have been regarded as the only symptom possibly indicative of TA before the diagnosis was made, nephrography was normal.

The case presented here, the few additional patients reported with a sarcoidosis preceding vasculitis, in general, and TA, in particular, as well as the two cases of sarcoidosis among 60 patients with $\mathrm{TA},{ }^{4}$ suggest that TA or arteritides similar to TA and sarcoidosis may be related diseases. Thus the concept of a "Takayasu syndrome" ${ }^{11}$ may have to be re-evaluated or at least to be seen as heterogeneous. Reports on Crohn's disease, another granulomatous disorder, with $\mathrm{TA}^{4}$ further support the possibility of a common basis of granulomatous disorders and TA. Cases such as that presented here should raise awareness of such possibilities, particularly in disorders whose cause(s) are still unknown.

Although the absolute number of similar cases reported is small, the relatively low prevalence of sarcoidosis, and even more so the rarity of aortitis, suggests that this number is relatively high and too high to be mere coincidence. In particular, the fact that in almost all these cases sarcoidosis preceded the vasculitic manifestations is a strong indication for a common basis. In fact, several authors have suggested that vasculitis may be a feature of sarcoidosis; however, such notions usually related to cutaneous vasculitis. ${ }^{5-8}$ Importantly, in some instances, a granulomatous angiitis was seen, ${ }^{5}$ and this points towards the possibility that even observations of concurrence of sarcoidosis with Wegener's granulomatosis may, in reality, also represent types of sarcoid vasculitis. The same may be true for the aortitis seen here and elsewhere. ${ }^{10}$

If all these aspects are taken into consideration, the fact that one rare feature of sarcoidosis may be vasculitis, and that this vasculitis may not be easily distinguishable from TA, in conjunction with the occurrence of TA-like disease in patients with past (or still active) sarcoidosis, raises the possibility that sarcoidosis and TA may be aetiopathogenetically related. Further analyses of this question may provide new insights, including a search for aetiological agents and possibly new causal therapeutic approaches.

1 Kerr GS. Takayasu's arteritis. Rheum Dis Clin North Am 1995;21:1041-57.

2 Pariser KM.Takayasu's arteritis. Curr Opin Cardiol 1994;9: 575-80.

3 Lupi-Herrera E, Sanchez-Torres G, Marcushamer J, Mispireta J, Horwitz S, Espino Vela J. Takayasu's arteritis. Review. Clinical study of 107 cases. Am Heart J
1977;93:94-103.

4 Kerr GS, Hallahan MS, Giordano J, Leavitt R, Fauci A, Rottem M, et al. Takayasu arteritis. Ann Intern Med 1994; 120:919-29.

5 Takemura T, Shishiba T, Akiyama O, Oritsu M, Matsui Y, Eishi Y. Vascular involvement in cutaneous sarcoidosis. Pathol Int 1997;47:84-9.

6 Watson I, Hill CM, Biggart JD, Russell CJ, Garrett PJ. Sarcoidosis and primary systemic vasculitis. Nephrol Dial Transplant 1996;11:1631-3.

7 Aractingi S, Cadranel J, Milleron B, Saiag P, Malepart MJ, Dubertret L. Sarcoidosis associated with leucocytoclastic vasculitis. A case report and review of the literature. Dermatology 1993;187:50-3.

8 Gran JT. Multiorgan sarcoidosis presenting with symmetric polyarthralgia, cutaneous vasculitis, and sicca symptoms. Scand J Rheumatol 1997;26:225-6.

9 Ahuja TS, Mattana J, Valderrama E, Sankaran R, Singhal PC, Wagner JD. Wegener's granulomatosis followed by PC, Wagner JD. Wegener's granulomatosis followed by
development of sarcoidosis. Am J Kidney Dis 1996;28: 893-8.

10 Rose CD, Eichenfeld AH, Goldsmith DP, Athreya BH. Early onset sarcoidosis with aortitis-“juvenile systemic granulomatosis?”. J Rheumatol 1990;17:102-10.

11 Maeda S, Murao S, Sugiyama T, Utaka I, Okamoto R. Generalized sarcoidosis with sarcoid aortitis. Acta Pathologica Japan 1982;58:386-9

12 Schapiro JM, Shpitzer S, Pinkhas J, Sidi Y, Arber N. Sarcoidosis as the initial manifestation of Takayasu arteritis. Case report. J Med 1994;25:121-8

13 Taieb A, Dufillot D, Pellegrin-Carloz B, Calabet A, Clementy J, Guillard JM, et al. Postgranulomatous anetoderma associated with Takayasu's arteritis in a child. Arch Dermatol 1987;123:796-800.

14 Lie JT. Isolated pulmonary Takayasu arteritis: clinicopathological characteristics. Mod Pathol 1996;9:469-74.

15 Jung EM, Baumann R, Rauh G, Müller-Höcker J. Unusual presentation of Takayasu arteritis with cardiac involvement and imitation of juvenile arteriosclerosis. A case report. Angiology 1996;47:399-406.

16 Emzenhauer RJ, West SG. Sarcoidosis in autoimmune disease. Semin Arthitis Rheum 1992;22:1-17. 